\title{
Editorial
}

\author{
Karen Nelson \\ Editor-in-Chief \\ Tracy Creagh \\ Journal Manager
}

\section{Welcome to 2021}

Despite the impact of COVID-19 across the tertiary education sector in 2020 (and continuing), we are pleased to be able to bring you our general issue for the year intact and without interruption. We are also reassured that our article submission rate remains constant despite the recent global disruption. The editorial team recognise that there has never been a more important time to share and disseminate current teaching and learning research. Authors are encouraged to submit research on practice that clearly identifies elements transferable to other domains and detail how a specific initiative contributes to the broader knowledge base. In this new COVID- normal learning environment, sharing learning and teaching initiatives in an open access forum has never been more valuable.

2021 will see the Journal resume to the normal publishing schedule of three issues:

This general issue collates accepted articles under the broad remit of student engagement, this time with authors from Australia, the U.S. Belgium and Ireland.

The second issue for 2021 is dedicated to those accepted peer reviewed articles submitted to the Journal in conjunction with the annual STARS Conference. After a COVID-19 enforced sabbatical in 2020, the STARS Conference returns with a 5-day online format (July 5-9).

The third issue presents articles and practice reports in a special issue curated by Professor Marcia Devlin and Dr Jade McKay. Student Success in a Global Pandemic will present empirical studies on pedagogical and support innovations and applications of evidence-based practices to online and remote teaching and learning and student support during a time of international crisis.

\section{Articles}

From Ireland, Natasha Daniels and Pádraig MacNeela explore the promoters and barriers to first year persistence and the student support needs in relation to these promoters and barriers. According to the authors, this is the first study in Ireland to work specifically with second year college students who have the lived experience of first year at college.

In Negative Affect and Performance on Exam Day in College Students: The Role of Self-Regulation, Alissa Russell, Kathleen Thursby, Teresa Aubele-Futch and Rebecca Stoddart investigate the mediating role of time-management-related selfregulatory behaviours on the relationship between trait emotion regulation and negative effect on the day of a first major exam in a sample of U.S. college students.

Except where otherwise noted, content in this journal is licensed under a Creative Commons Attribution 4.0 International Licence. As an open access journal, articles are free to use with proper attribution. ISSN: 2205-0795 
Technology-mediated communication with student is the topic of two papers. From the University of South Australia Sally Lewis, Georgina Heath, Lisa Lim and Rosie Roberts report on the impact of learning analytics data used to identify appropriate engagement metrics for personalising feedback to students. Results indicate an improvement in course grades and that students felt "noticed" as individual learners. Similarly, Sarah Dart and Belinda Spratt from Queensland University of Technology, Australia, implemented personalised emails in two first year mathematics courses as a scalable strategy for supporting students with diverse needs. Students perceived the personalised emails favourably and believed the intervention would contribute to them achieving better grades.

Gayani Samarawickrema and Kaye Cleary reiterate the value of a hybrid model for study in Block Mode Study: Opportunities and Challenges for a New Generation of Learners in an Australian University. The article is a follow-up to a previously published Feature Practice Report titled Re-building the first year experience, one block at a time (McCluskey et al., 2019) and serves to update the reader on the outcomes of the initiative based on two recent years of data from Victoria University, Australia.

David Birbeck, Lois McKellar and Kat Kenyon present one of the few studies from Australian practitioners that have sought to understand the "middle child"; the years in between the first and final year of study. In Moving Beyond First Year: An Exploration of Staff and Student Experience the authors bring together data from both teaching staff and students with the purpose of describing staff perceptions of students' experiences/challenges and exploring students' experiences of higher education beyond the first year of study.

From the University of Tasmania, Australia Michael Macartney, Pathmavathy Namasivayam and John Cooper aimed to determine whether student nurses regard the inclusion of video-simulation with critical-reflection as a valuable opportunity to develop their clinical-reasoning (CR) skills. A major theme identified in this study was that despite strong student agreement for the assessment task and use of video-simulation as an appropriate method to develop and recognise CR, this did not necessarily translate into their ability to confidently use CR skills in clinical placement.

In The Effect of a Face-To-Face ScienceReady Preparatory Short Course on University Students' Self-Efficacy, Jyothi Thalluri, Joy Penman and Minh Chau describe the impact of a health science preparatory course on a selection of students at an Australian metropolitan university. Evaluations of the course ScienceReady indicated that student anxiety levels starting first year university decreased significantly, the retention rate was higher, and students performed academically significantly better than students who had not done the short course.

\section{Practice Reports}

From Belgium, Simon Liénardy, Benoit Donnet and Laurent Leduc detail the evolution (over seven years) of a course targeting first year computer science students which introduces basic principles of computer science and, in particular, the basic principles of programming. The authors focused on engagement levels and the outcomes aligned to setting realistic expectations around course curriculum and workload.

Ameena Payne provides guidance and examples for online instructors to engage students within discussion boards in the digital realm. Ameena draws on her experiences at Swinburne Online to offer useful strategies to build engaging, sustainable learning conversations within discussion forums that are abundant with collaborative inquiry, dialogue and sharing of personal learning experiences for online students in higher education.

Finally, from the U.S., Cori Biddle reports on the early success of a technology training program designed to introduce incoming first-year students to the basics of academic technologies. This project highlights how librarians, particularly in a COVID-19 context, can be essential assets when designing a student training and technology program.

\section{References}

McCluskey, T., Weldon, J., \& Smallridge, A. (2019). Rebuilding the first year experience, one block at a time. A Practice Report. Student Success, 10(1), 1-15. https://doi.org/10.5204/ssj.v10i1.1148 


\section{Please cite this article as:}

Nelson, K., \& Creagh, T. (2021). Editorial. Student Success, 12(1), i-iii. https://doi.org/10.5204/ssj.1900

Student Success: A journal exploring the experiences of students in tertiary education 